\title{
The great chain of being
}

\author{
Our persistence in placing ourselves at the top of the Great Chain of Being suggests we have some \\ deep psychological need to see ourselves as the culmination of creation.
}

\section{Sean Nee}

For centuries the 'great chain of being' held a central place in Western thought. This view saw the Universe as ordered in a linear sequence starting from the inanimate world of rocks. Plants came next, then animals, men, angels and, finally, God. It was very detailed with, for example, a ranking of human races; humans themselves ranked above apes above reptiles above amphibians above fish. This view even predicted a world of invisible life in between the inanimate and the visible, living world, long before Antonie van Leeuwenhoek's discoveries. Although advocates of evolution may have stripped it of its supernatural summit, this view is with us still.

Common presentations of evolution mirror the great chain by viewing the process as progressive. For example, in their book The Major Transitions in Evolution, John Maynard Smith and Eors Szathmáry take us from the origin oflife, through to the origin of eukaryotic cells, multicellularity, human societies and, finally, of language. They explicitly point out that evolution does not necessarily lead to progress, and even refer to the great chain by its Latin name, scala naturae. But it is impossible to overlook the fact that the 'major' evolutionary transitions lead inexorably, step by step, to us. Similarly, in their recent essay in Nature, 'Climbing the co-evolution ladder' (431, 913; 2004), Lenton and colleagues illustrate their summary oflife-environment interactions through the ages with a ladder whose rungs progress through microbes, plants, and, at the top, large animals.

In his recent book The Ancestor's Tale, Richard Dawkins reverses the usual temporal perspective and looks progressively further back in time to find our ancestors. Like Maynard Smith and Szathmáry, he cautions us against thinking that evolution is progressive, culminating with us. He emphasizes that with whatever organism we begin the pilgrimage back through time, we all are reunited at the origin of life. But by beginning the journey with us and looking backwards along our ancestry, Dawkins generates a sequence of chapter titles that would read like a typical chain to a

medieval theologian, albeit with some novelties and the startling omission of God.

By starting with us, Dawkins regenerates the chain because species that are more dosely related to us are more similar as well, and such similarity was an important criterion in determining the rankings in the classical chain. But there is nothing about the world that compels us to think
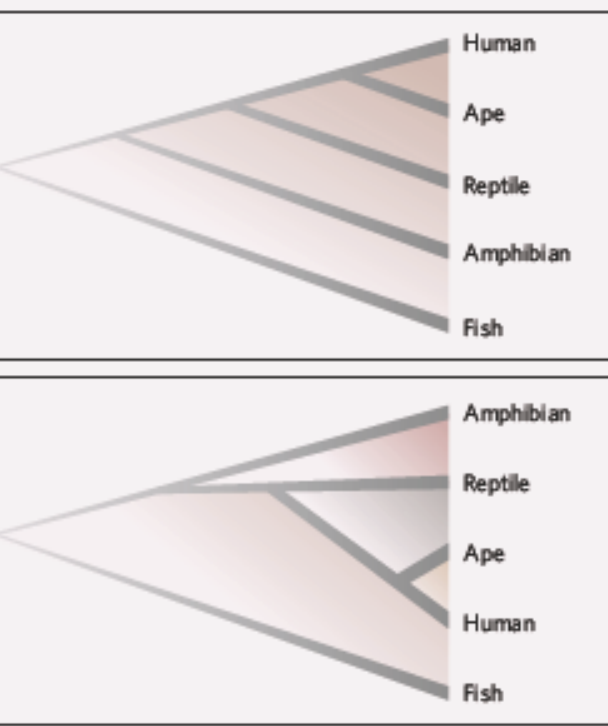

Although bothrepresentations are equally valid, we instinctively os ition ourselves at the top of phylogenetic trees (upper panel).

about it in this way, suggesting, instead, that we have some deep psychological need to see ourselves as the culmination of creation. Illustrating this, when we represent the relationships between species, including ourselves, in a family tree, we automatically construct it so that the column of species' names forms a chain with us as the top, as in the first of the trees pictured. But the other construction is equally valid.

Here is another view of evolution, but this time from the point of view of microbes - the main form oflife on our planet. From the mists of time, nearly 4 billion years ago, three great domains of life emerged: Bacteria, Archaea, and the molecular parasites of these, such as viruses. Over hundreds of millions of years the Bacteria evolved an extraordinary variety of biochemical capabilities, including the ability to generate light, and to 'eat' and 'breathe' metals. The Archaea also evolved remarkable capacities to thrive in every environment available, including superheated, pressurized water deep in the oceans.
Changes in ocean ecosystems wrought by Bacteria and Archaea contributed to the deposition of the ocean sediments, an event of enormous significance: these sediments became the habitat for bacteria that now constitute about one-third of the total living biomass today. (A side-effect of the deposition is the oxygenation of the atmosphere by photosynthetic bacteria.)

Evolution continued for billions of years, with many remarkable innovations stimulated by both cooperation and conflict. For example, Bacteria evolved the capacity to communicate chemically to coordinate attacks on others, and a willingness to commit suicide for the greater good of the community. Around a billion years ago, a great experiment occurred: Bacteria and Archaea came together in a fusion event to synthesize a whole new domain of life, the Eukarya. Sadly, the outcome was rather uninteresting: the resulting organisms displayed a very limited metabolic repertoire and much restricted habitat requirements.

Over the past 600 million years the Bacteria, Archaea and microbial Eukarya have continued to evolve into brand new niches. As it happens, a few branches of Eukarya - plants and animals - grew freakishly huge bodies. They also created both new substances for bacteria to exploit, such as plant lignins, and new environments for microbes to inhabit, such as feathers and urinary tracts. Indeed, some of the richest and most interesting ecologies on Earth can be found inside the animal gut.

One of the huge species, Homo sapiens, got remarkably self-important. But when, to his surprise, a virus wiped him out, most oflife on Earth took no notice at all.

Sean Nee is at the Institute of Evolutionary Biology, School of Biological Sciences, University of Edinburgh, West Mains Road, Edinburgh EH93JT, UK.

\section{FURTHER READING}

Lovejoy, A. O. The Great Chain of Being (Harper and Row, New York, 1965)

Gee, H. Nature 420, 611 (2002).

Maynard Smith 1 \& Szathmáry, E. The Major Transitions of Evolution (W. H. Freeman \& Co, Oxford, 1995)

Dawkins, R. The Ancestor's Tale (Weidenfeld \&

Nicolson, New York, 2004).

Nee, S.Nature 429,804-805 (2004) 